\title{
Genetic background determines the nature of immune responses and experimental immune-mediated blepharoconjunctivitis (EC)
}

\author{
O. Yoshida, H. Yoshida, H. Iwamoto, K. Nishino, A. Fukushima and H. Ueno \\ Laboratory of Immunology, Department of Ophthalmology, Kochi Medical School
}

\begin{abstract}
Purpose. Experimental immune-mediated blepharoconjunctivitis (EC) was induced in Lewis rats by immunization with ovalbumin (OVA) in complete Freund's adjuvant (CFA) or aluminum hydroxide $\left[\mathrm{Al}(\mathrm{OH})_{3}\right]$. To investigate the affect of genetic factors on the susceptibility of EC, we tested different strains of rats for the development of EC.

Methods. Lewis and Brown Norway (BN) rats were immunized once with $100 \mu \mathrm{g}$ of OVA in CFA or $\mathrm{Al}(\mathrm{OH})_{3}$. Three weeks later they were challenged with OVA in eye drops; 24 hours after the challenge they were sacrificed and their eyes, blood, and lymph nodes were harvested for histological studies, measurement of OVA-specific antibodies (IgG, IgG1, IgG2a, $\operatorname{IgE})$, and proliferation or cytokine assay, respectively. ELISA was used to detect OVA-specific IgG; passive cutaneous anaphylaxis was used for detecting IgE.

Results. EC, OVA-specific IgG, and cellular immunity were induced in Lewis rats by using either adjuvant, whereas $\operatorname{IgE}$ was not produced by either adjuvant. In contrast, $\operatorname{IgE}$ was produced in $\mathrm{BN}$ rats using either adjuvant, whereas cellular immunity was evoked only when CFA was used. Less cellular infiltration as well as cellular proliferation was detected in $\mathrm{BN}$ rats immunized with $\mathrm{Al}(\mathrm{OH})_{3}$. In both strains, $\mathrm{Al}(\mathrm{OH})_{3}$ induced a higher $\operatorname{IgG1} / \operatorname{IgG} 2 \mathrm{a}$ ratio than did CFA. More interferon- $\gamma$ by stimulation with OVA was noted in Lewis rats compared to BN rats, whereas interleukin- 4 was detected only in $\mathrm{BN}$ rats.
\end{abstract}

Conclusions. The severity of EC evaluated by cellular infiltration was dependent on OVA-specific cellular immunity. Genetic background is more important than adjuvants in determining the nature of EC and immunity.

Correspondence: Atsuki Fukushima, M.D., Ph.D., Laboratory of Immunology, Department of Ophthalmology, Kochi Medical School, Kohasu, Oko-cho, Nankoku 783-8505, Japan, Tel: +81-888-80-2391, Fax: +81-888-80-2392
Keywords: experimental immune-mediated blepharoconjunctivitis (EC), Th1, Th2, Lewis rat, Brown Norway rat, genetic background

\section{Introduction}

Experimental immune-mediated blepharoconjunctivitis (EC) was induced in Lewis rats by a topical challenge with ovalbumin (OVA) in eye drops after immunization with OVA in various adjuvants (1). The major histological feature of EC in Lewis rats was mononuclear cell infiltration in the palpebral conjunctiva (1). In addition to active immunization, the transfer of OVA-primed lymph node cells activated in vitro $(2,3)$ and a $\mathrm{CD}^{+} \mathrm{T}$ cell line specific to OVA peptide 323339 (3) was able to induce EC in recipient rats. Therefore, we concluded that EC in Lewis rats is a cellular immunitymediated disease, especially a $\mathrm{CD} 4^{+} \mathrm{T}$ cell-mediated disease. In contrast to the induction of strong cellular immunity with OVA-specific IgG production, little OVA-specific IgE was produced (4).

Lewis rats are susceptible to experimental organ-specific autoimmune diseases such as experimental autoimmune encephalomyelitis (4), experimental autoimmune uveoretinitis (5), and collagen-induced arthritis (6). These types of diseases are mediated by Th1-dominant immune responses $(7,8,9)$. Induction of Th2 immune responses either during the induction phase or the effector phase in animals with these diseases inhibited the development of the diseases $(10,11)$. In contrast to Th1-dominant immunity induced in Lewis rats, Brown Norway (BN) rats are susceptible to experimental systemic autoimmune diseases such as mercuric chloride $\left(\mathrm{HgCl}_{2}\right)$-induced autoimmune disease (12) and experimental allergic airway responses (13), which are related to Th2-dominant immune responses $(14,15)$. These data strongly suggest that genetic background determines the nature of the induced immune responses and leads to a high susceptibility of certain types of diseases (16). 
Adjuvants are also known to be important for provoking immune responses. Complete Freund's adjuvant (CFA) (17) is often used to induce delayed-type hypersensitivity and therefore is used to induce organ-specific autoimmune diseases, such as experimental autoimmune encephalomyelitis (18). Aluminum hydroxide $\left[\mathrm{Al}(\mathrm{OH})_{3}\right](19)$ is often used to induce $\mathrm{IgE}$ and therefore is used to induce experimental allergic diseases. Pretreatment with an autoantigen in $\mathrm{Al}(\mathrm{OH})_{3}$ inhibited the development of collagen-induced arthritis (20), indicating that the collagen-specific Th2 immune responses induced by $\mathrm{Al}(\mathrm{OH})_{3}$ inhibited disease-inducing Th1 responses.

These lines of information prompted us to investigate the involvement of both genetic background and adjuvants in the development of EC. We compared both EC and immune responses in Lewis and $\mathrm{BN}$ rats immunized with OVA in either $\mathrm{CFA}$ or $\mathrm{Al}(\mathrm{OH})_{3}$. The data presented here demonstrated that genetic background primarily determines Th1/Th2 dominance and that the effects of adjuvants are secondary. Furthermore, the intensity of cellular immunity was dependent on adjuvant and was related to the severity of cellular infiltration in EC.

\section{Materials and methods}

\section{Rats}

Six- to 8-week-old male Lewis rats and Sprague-Dawley (SD) rats (Seac Yoshitomi, Fukuoka, Japan) and BN rats (Clea Japan, Inc., Tokyo, Japan) were maintained in a pathogenfree animal facility at Kochi Medical School. All animal procedures conformed to institutional guidelines and to the ARVO Resolution on Use of Animals in Research.

\section{Antigens}

OVA (grade V, Sigma Immunochemicals, St. Louis, MO) was used for either immunizing or challenging antigens. Concanavalin A (Con A, Sigma Immunochemicals, St. Louis, MO) was used for a mitogen in vitro.

\section{Sensitization, challenge, and evaluation of EC}

Lewis and $\mathrm{BN}$ rats were injected subcutaneously with 100 $\mu \mathrm{g}$ of OVA in either CFA (Yatoron, Tokyo, Japan) or $\mathrm{Al}(\mathrm{OH})_{3}$. Three weeks later the rats were challenged with OVA by eye drops as previously reported $(1,2,3)$. Twentyfour hours after being challenged, rats were clinically evaluated and sacrificed, and their eyes, blood, and lymph nodes were harvested for histological studies, measurement of antibody production, and a proliferation assay, respectively. In brief, the eyes including the lids were fixed in $10 \%$ buffered formalin and embedded in paraffin. Sections $10 \mu \mathrm{m}$ thick were stained with hematoxylin-eosin and the infiltrated cells were counted in the palpebral conjunctiva with an eye piece grid of $\times 400$ magnification $(1,2,3)$.

\section{Assessment for cellular immune responses of primed lymph node cells}

Lymph nodes were combined for each group and experiments were repeated at least three times. Lymphocyte proliferation assays were set up in quadruplicate in 96-well flat-bottom plates. Lymph node cells $\left(3 \times 10^{5}\right.$ cells/well $)$ were cultured in a final volume of $0.2 \mathrm{ml}$ RPMI 1640 medium supplemented with $5 \%$ fetal calf serum (ICN Biomedical Japan Co., Tokyo, Japan), 2-mercaptoethanol $\left(5 \times 10^{-5} \mathrm{M}\right)$, L-glutamine (2 $\mathrm{mM})$, penicillin $(100 \mathrm{U} / \mathrm{ml})$, and streptomycin $(100 \mu \mathrm{g} /$ ml). Cells were stimulated with OVA at final concentrations of $0.1,1,10$, and $100 \mu \mathrm{g} / \mathrm{ml}$. After incubation for 72 hours at $37{ }^{\circ} \mathrm{C}$ in a humidified atmosphere with $5 \% \mathrm{CO}_{2}$, cultures were pulsed for 16 hours with $0.5 \mu \mathrm{Ci} /$ well of ${ }^{3} \mathrm{H}$-thymidine (Japan Atomic Energy Research Institute, Tokai, Japan). Cultures were then harvested and the radioactivity was measured by standard techniques. Data were expressed as stimulation indices.

\section{Detection of OVA-specific IgG by ELISA}

Serum was collected from each rat via cardiac puncture at the time of death. Serum antibody levels against OVA were measured by direct ELISA. OVA (500 $\mathrm{ng} /$ well for total $\mathrm{IgG}$ and $5 \mu \mathrm{g} /$ well for IgG1 or IgG2a) was absorbed to 96 -well plates for 2 hours at $37{ }^{\circ} \mathrm{C}$. The plates were washed with PBS-Tween, and serially diluted serum samples were added to the wells. Bound antibody was detected by peroxidaseconjugated anti-IgG (Nordic Immunological Laboratories, Tilburg, The Netherlands) or peroxidase-conjugated anti-IgG1 or anti-IgG2a (Pharmingen, San Diego, CA). The plates were developed by using 3,3',5,5'-tetramethylbenzidine base (TMBELISA, GIBCO BRL, Gaithersburg, MD) and the optical density (OD) of each well was read at $610 \mathrm{~nm}$. Data were presented as the ratio (IgG1/IgG2a) of the OD $610 \mathrm{~nm}$ values of the 1:160 dilution.

\section{Detection of OVA-specific IgE by passive cutaneous anaphylaxis (PCA)}

Male SD rats were used to determine the skin-sensitizing capacity of serum from immunized Lewis or BN rats. Dorsal surfaces of unsensitized SD rats were shaved, and serially diluted serum was injected intradermally (dose volume $0.1 \mathrm{ml}$ ). After a latent period of 48 hours, each rat received an intravenous injection of $1 \mathrm{mg}$ OVA and $2.5 \mathrm{mg}$ Evans' blue dye in $1 \mathrm{ml}$ of PBS. Rats were killed after 30 minutes, the dorsal skin was removed, and reactions were evaluated on the inner skin surface (21).

\section{Cytokine ELISA using culture supernatant}

Lymph nodes from OVA-primed rats were combined for culture. Cells were prepared as described above; $1 \times 10^{6}$ cells were cultured for 2 days in 96-well flat-bottom plates with either OVA at $50 \mu \mathrm{g} / \mathrm{ml}$ or Con A at $1 \mu \mathrm{g} / \mathrm{ml}$ in a final vol- 


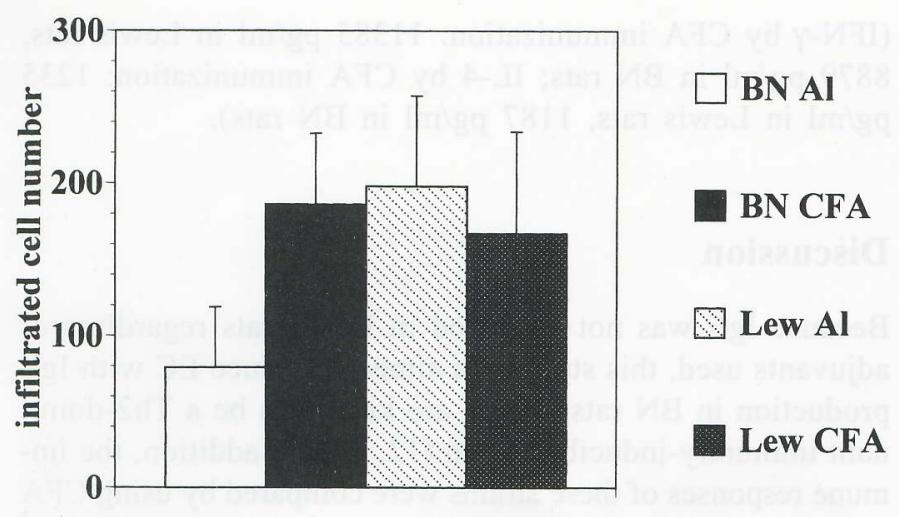

Figure 1. Both adjuvant and genetic background are related to the severity $\mathrm{EC}$. Both Lewis and $\mathrm{BN}$ rats were immunized with OVA in either CFA or $\mathrm{Al}(\mathrm{OH})_{3}$ following topical challenge with OVA by eye drops. Infiltrated cells were counted per field in the palpebral conjunctiva. Infiltrated cells in $\mathrm{BN}$ rats immunized with $\mathrm{Al}(\mathrm{OH})_{3}$ exhibited statistically fewer than other three groups $(p=0.002)$, while there was no difference between these three groups $(p>0.25)$. The experiments were combined and each group consists of 6 to 8 rats.

ume of $10 \mathrm{ml}$ RPMI1640 medium containing $5 \times 10^{-5} \mathrm{M}$ of 2-mercaptoethanol and 5\% fetal calf serum. Culture supernatants were harvested and assayed by commercial cytokine ELISA (BioSource International, Camarillo, CA) for interferon- $\gamma($ IFN- $\gamma$ ) or interleukin-4 (IL-4) by strict adherence to the recommended method.

\section{Statistical analysis}

Statistical comparisons of the number of infiltrated cells, $\mathrm{IgE}$ titers, and $\mathrm{IgG1} / \mathrm{IgG} 2 \mathrm{a}$ ratios were performed by Student's $t$-test.

\section{Results}

Lewis rats were prone to EC regardless of adjuvants used whereas severe cellular infiltration was inducible in BN rats only by CFA

Because EC is evaluated by the number of infiltrated cells, inflammatory cell counts in the palpebral conjunctiva were used to compare the severity of EC in each group. The infiltrated cell number in the conjunctiva of Lewis rats either immunized with CFA or $\mathrm{Al}(\mathrm{OH})_{3}$ was similar to that of $\mathrm{BN}$ rats immunized with CFA (Figure 1). There were no statistical differences among these three groups $(0.902<\mathrm{P}<$ 0.979). Compared with these massive cellular infiltrations, statistically fewer cells $(0.007<\mathrm{P}<0.011)$ were detected in the conjunctiva of $\mathrm{BN}$ rats immunized with $\mathrm{Al}(\mathrm{OH})_{3}$ (Figure 1). In addition, the percentage of eosinophils (of the total number of infiltrated cells) was much higher in these rats than in the other three groups of rats (Figure 2, $\mathrm{A}$ and B). There were no apparent differences in the number of infiltrating eosinophils among the other three groups

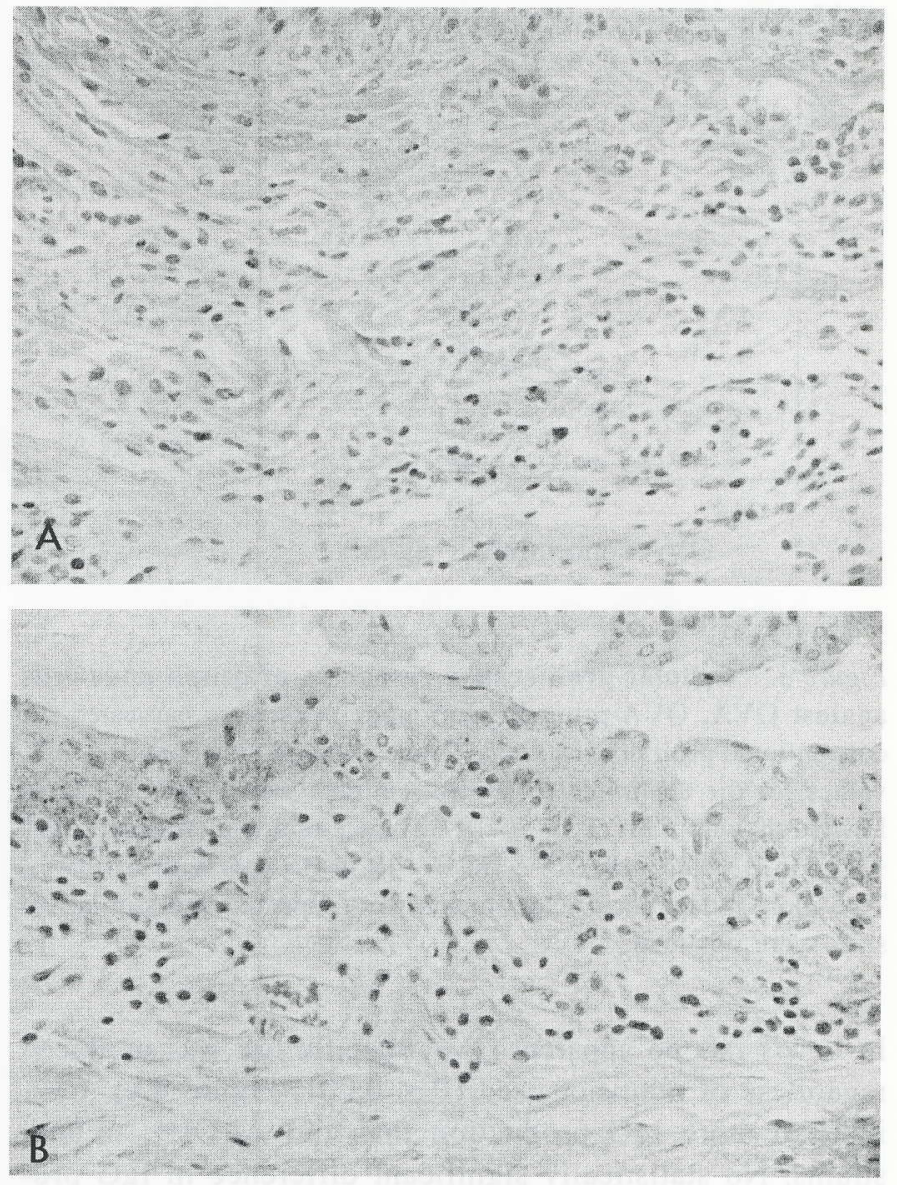

Figure 2. Histological features of cellular infiltration in the conjunctiva. Massive cellular infiltration, predominantly mononuclear cell infiltration, was demonstrated in Lewis rats immunized OVA in CFA (A). In contrast, less cellular infiltration was seen in BN rats immunized OVA in $\mathrm{Al}(\mathrm{OH})_{3}(\mathrm{~B})$. It should be noted that about $40 \%$ of infiltrated cells were eosinophils in this group (B). Sections, were stained with H.E. and the magnification was $\times 320$.

(Figure 2B) and, as previously reported (1), most of the infiltrated cells in these groups were mononuclear cells.

\section{Comparison of cellular immunity among the four groups}

Lymph node cells from Lewis rats immunized with either CFA or $\mathrm{Al}(\mathrm{OH})_{3}$ responded vigorously to OVA (Figure 3 ). In contrast, lymph node cells from $\mathrm{BN}$ rats immunized with $\mathrm{Al}(\mathrm{OH})_{3}$ did not proliferate even though cells immunized with CFA proliferated similarly to cells in Lewis rats (Figure 3). It should be noted that there is a close relationship between the severity of cellular infiltration and cellular proliferation against OVA (Figures 1 and 3).

IgG production depended on adjuvant used whereas IgE production depended on genetic background

OVA-specific IgE tested by PCA was detected in serum from $\mathrm{BN}$ rats immunized with either adjuvant (Figure $4 \mathrm{~A}) . \mathrm{Al}(\mathrm{OH})_{3}$ induced more OVA-specific IgE than did CFA $(\mathrm{P}=0.046)$. 


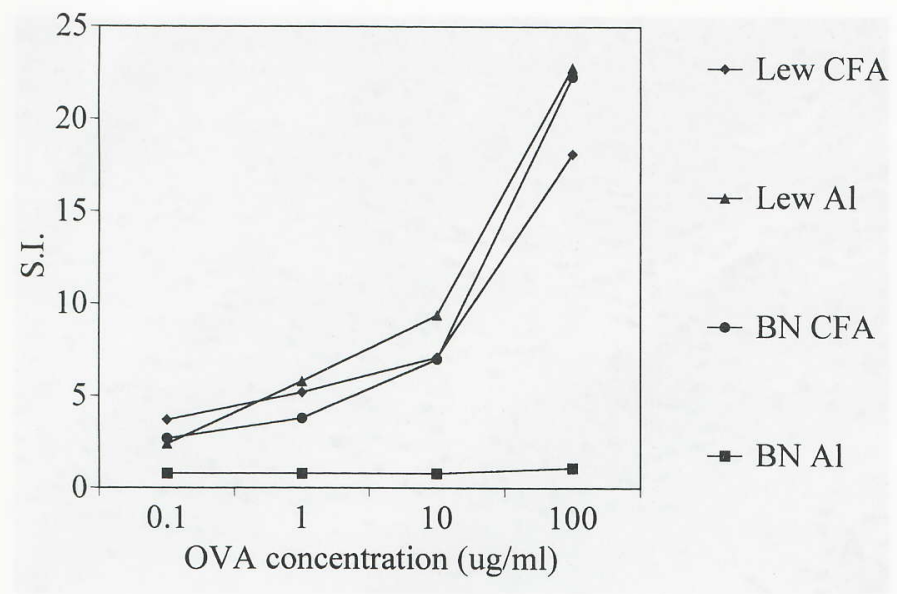

Figure 3. Cellular proliferative responses of lymph node cells against OVA. OVA-primed lymph node cells were harvested for conventional proliferation assay. The combined mean $\mathrm{cpm}+/$ - S.E. values for the unstimulated control cultures were : $461+/-26$ in Lewis rats with CFA; $821+/-19$ in Lewis rats with $\mathrm{Al}(\mathrm{OH})_{3}, 231$ $+/-11$ in $\mathrm{BN}$ rats with $\mathrm{CFA}$; $189+/-19$ in $\mathrm{BN}$ rats with $\mathrm{Al}(\mathrm{OH})_{3}$. Two more independent experiments were repeated and similar results were obtained.

In Lewis rats no apparent OVA-specific $\operatorname{IgE}$ was produced regardless of adjuvant used ( $\mathrm{P}<0.001$, Figure 4A). CFA induced more $\operatorname{IgG}$ production than $\operatorname{did} \mathrm{Al}(\mathrm{OH})_{3}$ in both strains. No statistically significant difference in IgG production was demonstrated between the two adjuvants in Lewis rats. The amount of OVA-specific IgG produced in serum by $\mathrm{Al}(\mathrm{OH})_{3}$ immunization was similar for two strains, whereas CFA immunization produced more OVA-specific IgG in the serum of $\mathrm{BN}$ rats than in the serum of Lewis rats (Figure 4B). In addition, the $\operatorname{IgG} 1 / \operatorname{IgG} 2$ a ratio was also the same for the two strains; that is, the ratio was around 1 when CFA was used and was around 3 when $\mathrm{Al}(\mathrm{OH})_{3}$ was used (Figure $4 \mathrm{C}$ ), although the differences among the four groups was not statistically significant $(\mathrm{P}>0.083)$.

\section{Genetic background but not adjuvant determines the cytokine profiles}

Culture supernatant was collected after 48 hours and assayed by using commercial cytokine ELISA. The data presented in Figure 5 (A and B) were obtained from culture supernatant of lymph node cells from both strains of rats immunized with OVA in CFA but not $\mathrm{Al}(\mathrm{OH})_{3}$. More IFN- $\gamma$ was produced by stimulation with OVA in Lewis rats than in BN rats $(P=0.019)$ and no difference in IFN- $\gamma$ production between the two adjuvants was detected (Figure $5 \mathrm{~A}$ and unpublished result). In contrast, stimulation with OVA only produced IL-4 in BN rats; IL-4 was below a detectable level in Lewis rats (Figure 5B). In $\mathrm{BN}$ rats, $\mathrm{CFA}$ induced more IL-4 production than did $\mathrm{Al}(\mathrm{OH})_{3}$ (data not shown). Stimulation with Con $\mathrm{A}$ induced vigorous production of both cytokines in both strains of rats regardless of adjuvants used
(IFN- $\gamma$ by CFA immunization: $11385 \mathrm{pg} / \mathrm{ml}$ in Lewis rats, $8879 \mathrm{pg} / \mathrm{ml}$ in BN rats; IL-4 by CFA immunization: 1235 $\mathrm{pg} / \mathrm{ml}$ in Lewis rats, $1187 \mathrm{pg} / \mathrm{ml}$ in BN rats).

\section{Discussion}

Because IgE was not produced in Lewis rats regardless of adjuvants used, this study was aimed to induce $\mathrm{EC}$ with $\operatorname{IgE}$ production in BN rats, which are known to be a Th2-dominant immunity-inducible strain $(12,13)$. In addition, the immune responses of these strains were compared by using CFA (17) and $\mathrm{Al}(\mathrm{OH})_{3}(19)$, which are known to induce Th1 and Th2, respectively.

Although Lewis rats are susceptible to Th1-mediated diseases whereas $\mathrm{BN}$ rats are susceptible to Th2-mediated diseases $(4,5,12,13)$, the factors responsible for the observed genetic difference in immune responses between $\mathrm{BN}$ rats and Lewis rats have not been clearly established. Roos et al. (22) attributed the different immune responses in these two strains to the different expression of major histocompatibility complex (MHC) class II molecules. Cytokine pattern (IFN- $\gamma /$ IL-4) is obviously involved in these genetic differences, yet there has been little information about which factors determine cytokine profile. Several nuclear factors were recently identified as key molecules for the induction of Th2-type cytokine production $(23,24)$. These factors as well as different expressions of MHC class II molecules may be involved in the genetic differences.

The data for the production of $\operatorname{IgG}$ and its subclass (Figure 4B) could be interpreted as indicating that adjuvants were able to determine the quantity and quality of the IgG produced. Although there has been no consensus that the IgG1/ IgG2a ratio is related to the Th2/Th1 relationship in rats, several reports support the concept of a positive relationship between the $\operatorname{IgG} 1 / \operatorname{IgG} 2 \mathrm{a}$ ratio and Th2/Th1 dominance (25, 26). From our data it could be suggested that despite the genetic background of rats, CFA was apt to induce Th1dominant OVA-specific IgG production, whereas $\mathrm{Al}(\mathrm{OH})_{3}$ was inclined to induce Th2-dominant OVA-specific IgG production. It should be noted that the total amount of OVAspecific IgG1 was higher in CFA-treated rats than in $\mathrm{Al}(\mathrm{OH})_{3}$ treated rats, even though the ratio of IgG1/IgG2a was higher in $\mathrm{Al}(\mathrm{OH})_{3}$-treated rats. Therefore, it could be concluded that the quality as well as the quantity of OVA-specific humoral immunity was determined by the adjuvants used.

By contrast, IgE, whose induction depends on Th2 immune responses $(19,27)$, was produced only in $\mathrm{BN}$ rats regardless of the adjuvant used (Figure 4A). The discrepancy between the $\operatorname{IgG} 1 / \operatorname{IgG} 2 \mathrm{a}$ ratio and $\mathrm{IgE}$ production (Figure 4, A and C) may be attributed to the immunization dose, because it is known that low doses induce high titers of $\operatorname{IgE}$ antibodies $(28,29)$. To examine this notion, $1 \mu \mathrm{g}$ of OVA with $\mathrm{Al}(\mathrm{OH})_{3}$ was used to immunize Lewis rats. There was no remarkable difference in OVA-specific IgE production (data not shown), further suggesting that Lewis rats are resistant to IgE production. Therefore, it could be concluded 


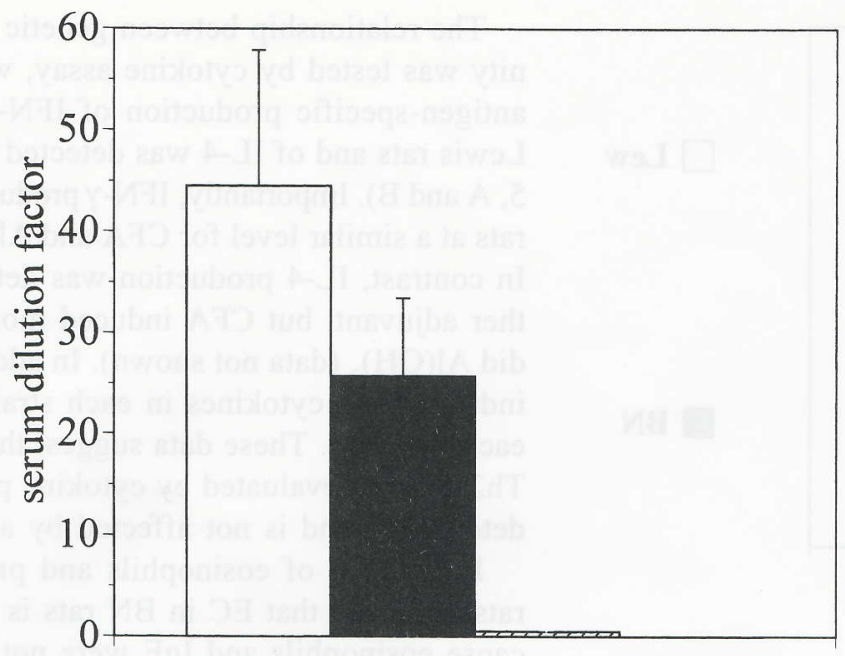

$\mathrm{BN} \mathrm{Al}$

BN CFA

$\square$ Lew AL

Lew CFA

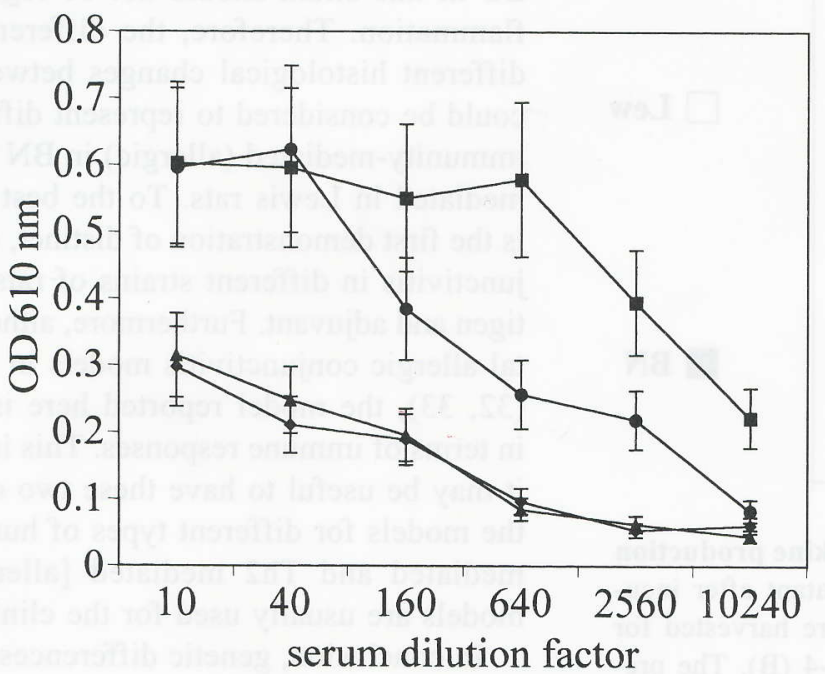

- BN CFA

- Lew CFA

$\triangle \mathrm{BN} \mathrm{Al}$

$\rightarrow$ Lew Al

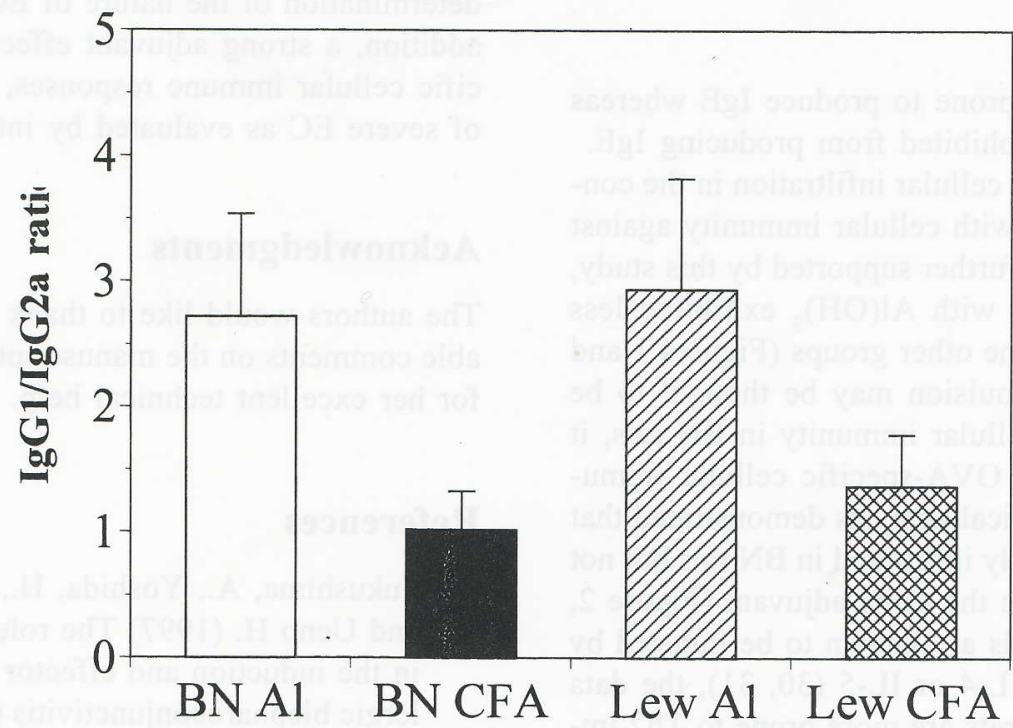

Figure 4. Involvement of both adjuvant and genetic background in OVA-specific antibody production. A: IgE titers were detected by passive cutaneous anaphylaxis (PCA) and all the data were combined and presented as positive mean dilution +/- S.D.. B: Total IgG titers were detected by direct ELISA. One representative data was presented and two more independent experiments were performed. C: IgG subclass titers were detected by direct ELISA. Data were presented as IgG1/IgG2a ratio of OD610 nm at the serum dilution of 160 . Similar results were obtained in other two experiments. 

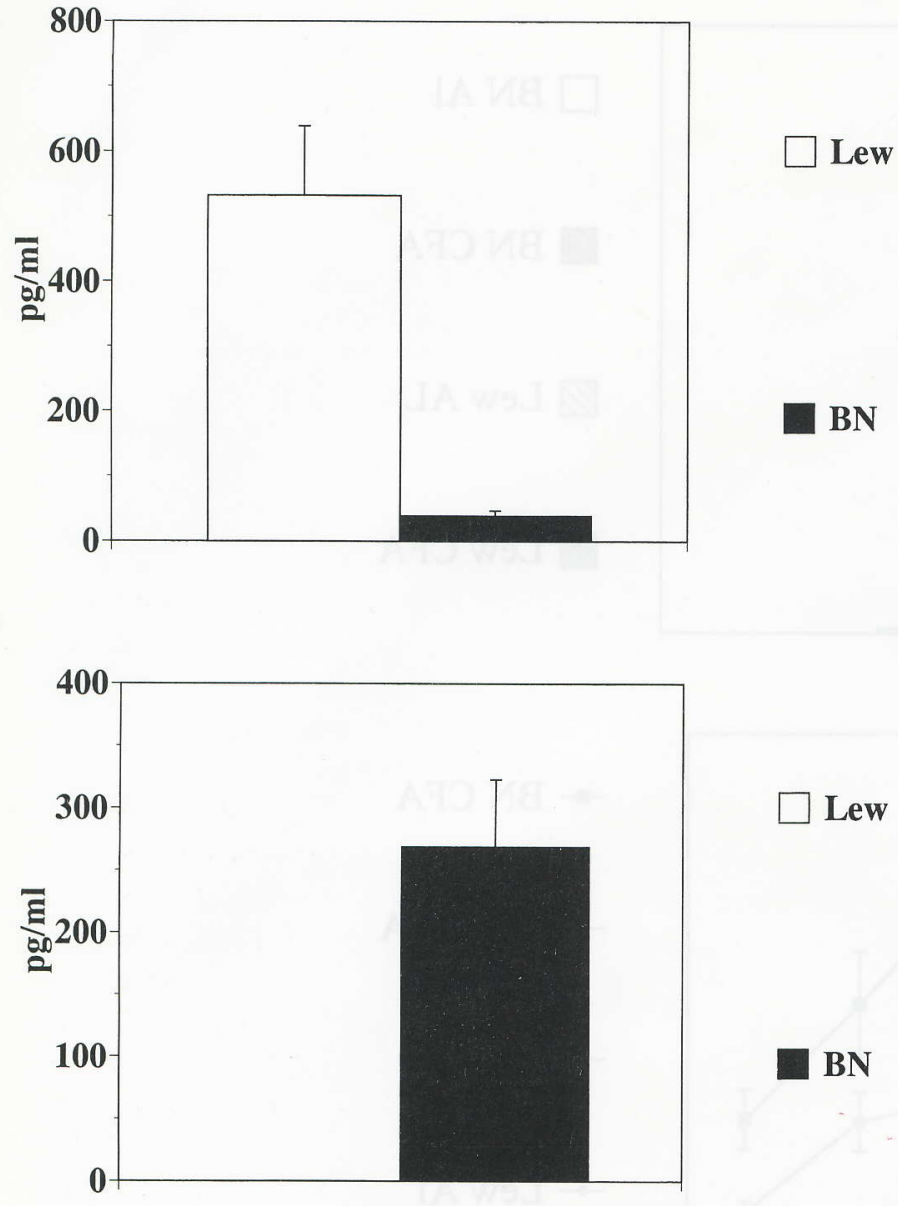

Figure 5. Genetic background determines cytokine production by antigen-specific stimulation. Culture supernatant after incubation in the presence of OVA for 48 hours were harvested for cytokine ELISA to detect either IFN- $\gamma$ (A) or IL-4 (B). The presented data was mean +/- S.D. of three independent experiments.

that $\mathrm{BN}$ rats are genetically prone to produce $\operatorname{IgE}$ whereas Lewis rats are genetically prohibited from producing IgE.

As we previously reported, cellular infiltration in the conjunctiva occurred in parallel with cellular immunity against OVA $(1,2)$. This notion was further supported by this study, because $\mathrm{BN}$ rats immunized with $\mathrm{Al}(\mathrm{OH})_{3}$ exhibited less cellular infiltration than did the other groups (Figures 1 and $3)$. Although the $\mathrm{Al}(\mathrm{OH})_{3}$ emulsion may be thought to be not sufficient for inducing cellular immunity in BN rats, it was able to induce vigorous OVA-specific cellular immunity in Lewis rats. Histochemical analysis demonstrated that eosinophils were predominantly infiltrated in $\mathrm{BN}$ rats but not in Lewis rats immunized with the same adjuvant (Figure 2, A and B). Because eosinophils are known to be induced by Th2-type cytokines such as IL-4 or IL-5 $(30,31)$, the data here further suggest that BN rats are more prone to Th2 immunity than are Lewis rats. Although the reason is not clear, it is noteworthy that there are discrepancies between cytokine pattern and $\operatorname{IgG} 1 / \operatorname{IgG} 2 \mathrm{a}$ ratio in Lewis rats immunized with $\mathrm{Al}(\mathrm{OH})_{3}$ and $\mathrm{BN}$ rats immunized with CFA (Figures $4 \mathrm{C}$ and 5B).
The relationship between genetic background and immunity was tested by cytokine assay, which demonstrated that antigen-specific production of IFN- $\gamma$ was detected only in Lewis rats and of IL-4 was detected only in BN rats (Figure $5, \mathrm{~A}$ and B). Importantly, IFN- $\gamma$ production was noted in Lewis rats at a similar level for CFA and $\mathrm{Al}(\mathrm{OH})_{3}$ (data not shown). In contrast, IL-4 production was detected in $\mathrm{BN}$ rats by either adjuvant, but CFA induced more IL-4 production than did $\mathrm{A} 1(\mathrm{OH})_{3}$ (data not shown). In addition, mitogenic stimuli induced both cytokines in each strain at a similar level for each cytokine. These data suggest that antigen-specific Th1/ Th2 balance evaluated by cytokine production is genetically determined and is not affected by adjuvant.

Infiltration of eosinophils and production of $\operatorname{IgE}$ in $\mathrm{BN}$ rats indicated that $\mathrm{EC}$ in $\mathrm{BN}$ rats is an allergic disease. Because eosinophils and IgE were not detected in Lewis rats, EC in this strain should not be regarded as an allergic inflammation. Therefore, the different responses as well as different histological changes between Lewis and $\mathrm{BN}$ rats could be considered to represent different types of EC: Th2 immunity-mediated (allergic) in BN rats and Th1 immunitymediated in Lewis rats. To the best of our knowledge, this is the first demonstration of distinct, different models of conjunctivitis in different strains of rats by using the same antigen and adjuvant. Furthermore, although several experimental allergic conjunctivitis models in rats have been reported $(32,33)$, the model reported here is the best characterized in terms of immune responses. This information suggests that it may be useful to have these two different types of EC as the models for different types of human conjunctivitis (Th1 mediated and Th2 mediated [allergic]), because disease models are usually used for the clinical trials of new drugs.

In conclusion, genetic differences between Lewis and BN rats are more important than adjuvant differences in the determination of the nature of EC and Th1-Th2 balance. In addition, a strong adjuvant effect, in terms of antigen-specific cellular immune responses, is related to the induction of severe EC as evaluated by intense cellular infiltration.

\section{Acknowledgments}

The authors would like to thank Dr. Yasushi Itoh for valuable comments on the manuscript and Ms. Natsuko Naruoka for her excellent technical help.

\section{References}

1. Fukushima, A., Yoshida, H., Iwamoto, H., Yoshida, O. and Ueno H. (1997) The role of cellular immunity both in the induction and effector phases of experimental allergic blepharoconjunctivitis (EAC) in rats. Exp Eye Res. 65, 631-637.

2. Yoshida, H., Yoshida, O., Iwamoto, H., Nishino, K., Hashida, M., Fukushima A. and Ueno, H. (1998) Analysis of effects of stimulation in vitro of ovalbumin (OVA) primed lymph node cells on adoptive transfer of experi- 
mental immune-mediated blepharoconjunctivitis (EC) in Lewis rats. Br. J. Ophthalmol., in press.

3. Fukushima, A., Nishino, K., Yoshida, O. and Ueno H. (1998) Characterization of the immunopathogenic responses to ovalbumin (OVA) peptide 323-339 in experimental immune-mediated blepharoconjunctivitis (EC) in Lewis rats. Curr. Eye Res. 17, 763-769.

4. McFarlin, D.E., Hsu, S.C., Slemenda, S.B., Chou, C.H. and Kibler, R.F. (1975) The immune response against an encephalitogenic fragment of guinea pig basic protein in the Lewis and Brown Norway strains of rat. $J$. Immunol. 115, 1456-1458.

5. Mochizuki, M., Kuwabara, T., Chan, C.C., Nussenblatt, R.B., Metcalfe, D.D. and Gery, I. (1984) An association between susceptibility to experimental autoimmune uveitis and choroidal mast cell numbers. J. Immunol. 133, 16991701 .

6. Holmdahl, R., Vingsbo, C., Hedrich, H., Karlsson, M., Kvick, C., Goldschmidt, T.J. and Gustafsson, K. (1992) Homologous collagen-induced arthritis in rats and mice are associated with structurally different major histocompatibility complex DQ-like molecules. Eur. J. Immunol. 22, 419-424.

7. Weinberg, A.D., Wallin, J.J., Jones, R.E., Sullivan, T.J., Bourdette, D.N., Vandenbark, A.A. and Offner, H. (1994) Target organ-specific up-regulation of the MRC OX-40 marker and selective production of Th1 lymphokine mRNA by encephalitogenic $\mathrm{T}$ helper cells isolated from the spinal cord of rats with experimental autoimmune encephalomyelitis. J. Immunol. 152, 4712-4721.

8. Renno, T., Zeine, R., Girard, J.M., Gillani, S., Dodelet, V. and Owens, T. (1994) Selective enrichment of Th1 CD45RBlow CD4+ T cells in autoimmune infiltrates in experimental allergic encephalomyelitis. Int. Immunol. 6, 347-354.

9. De Carli, M., D’Elios, M.M., Zancuoghi, G., Romagnani, S. and Del Prete, G. (1994) Human Th1 and Th2 cells: functional properties, regulation of development and role in autoimmunity. Autoimmunity 18, 301-308.

10. Racke, M.K., Bonomo, A., Scott, D.E., Cannella, B., Levine, A., Raine, C.S., Shevach, E.M. and Rocken, M. (1994) Cytokine-induced immune deviation as a therapy for inflammatory autoimmune disease. J. Exp, Med. 180, 1961-1966.

11. Trembleau, S., Penna, G., Gregori, S., Gately, M.K. and Adorini, L. (1997) Deviation of pancreas-infiltrating cells to Th2 by interleukin-12 antagonist administration inhibits autoimmune diabetes. Eur. J. Immunol. 27, 23302339.

12. Gillespie, K.M., Saoudi, A., Kuhn, J., Whittle, C.J. Druet, P., Bellon, B. and Mathieson, P.W. (1996) Th1/Th2 cytokine gene expression after mercuric chloride in susceptible and resistant rat strains. Eur. J. Immunol. 26, 2388-2392.

13. Vento, K.L., Dearman, R.J., Kimber, I., Basketter, D.A. and Coleman, J.W. (1996) Selectivity of IgE responses, mast cell sensitization, and cytokine expression in the immune response of Brown Norway rats to chemical allergens. Cell. Immunol. 172, 246-253.

14. Umetsu, D.T. and DeKruyff, R.H. (1997) Th1 and Th2 CD4+ cells in the pathogenesis of allergic disease. Proc. Soc. Exp. Biol. Med. 215, 11-20.

15. Druet, E., Praddaude, F., Duret, P. and Dietrich, G. (1998) Non-immunoglobulin serum proteins prevent the binding of IgG from normal rats and from rats with Th2mediated autoimmune glomerulonephritis to various autoantigens including glomerular antigens. Eur. J. Immunol. 28, 183-192.

16. Charlton, B. and Lafferty, K.J. (1995) The Th1/Th2 balance in autoimmunity. Curr. Opinion Immunol. 7, 793798.

17. Weiner, G.J., Liu, H.M., Wooldridge, J.E., Dahle, C.E. and Krieg, A.M. (1997) Immunostimulatory oligodeoxynucleotides containing the $\mathrm{CpG}$ motif are effective as immune adjuvants in tumor antigen immunization. Proc. Natl. Acad. Sci. U.S.A. 94, 10833-10837.

18. Maatta, J.A., Eralinna, J.P., Roytta, M., Salmi, A.A. and Hinkkanen, A.E. (1996) Physical state of the neuroantigen in adjuvant emulsions determines encephalitogenic status in the BALB/c mouse. J. Immunol. Meth. 190, 133141.

19. Victoratos, P., Yiangou, M., Avramidis, N. and Hadjipetrou, L. (1997) Regulation of cytokine gene expression by adjuvants in vivo. Clin. Exp. Immunol. 109, 569-578.

20. Mattsson, L., Lorentzen, J.C., Svelander, L., Bucht, A., Nyman, U., Klareskog, L. and Larsson, P. (1997) Immunization with alum-collagen II complex suppresses the development of collagen-induced arthritis in rats by deviating the immune response. Scand. J. Immunol. 46, 619-624.

21. Meng, A.L., Pinckard, R.N. and Halonen, M. (1973) Ontogeny of the release and reactivity to the mediators of IgE-induced acute allergic reactions in the rabbit: the homologous PCA reaction. J. Immunol. 110, 1554-1561.

22. Roos, A., Schilder-Tol, E.J.M., Chand, M.A., Claessen, N., Lakkis, F.G., Pascual, D.W., Weening, J.J. and Aten, J. (1998) Differential regulation of expression of the MHC class II molecules RT1.B and RT1.D on rat B lymphocytes: effects of interleukin-4, interleukin-13 and interferon- $\gamma$. Immunology, 93, 33-40.

23. Ho, I-C., Hodge, M.R., Roone, J.W. and Glimcher, L.H. (1996) The proto-oncogene c-maf is responsible for tissue specific expression of interleukin-4. Cell, 85, 973983.

24. Rincon, M., Anguita, J., Nakamura, T., Fikrig, E. and Flavell, R.A. (1997) Interleukin (IL)-6 directs the differentiation of IL-4-producing CD4+ T cells. J. Exp. Med. 185, 461-469.

25. Mussener, A., Lorentzen, J.C., Kleinau, S. and Klareskog, L. (1997) Altered Th1/Th2 balance associated with nonmajor histocompatibility complex genes in collagen-induced arthritis in resistant and non-resistant rat strains. Eur. J. Immunol. 27, 695-699. 
26. Gracie, J.A. and Bradley, J.A. (1996) Interleukin-12 induces interferon-gamma-dependent switching of IgG alloantibody subclass. Eur. J. Immunol. 26, 1217-1221.

27. Finkelman, F.D., Katona, I.M., Urban, J.F.Jr., Holmes, J., Ohara, J., Tung, A.S., Sample, J. V. and Paul, W.E. (1988) IL-4 is required to generate and sustain in vivo IgE responses. J. Immunol. 141, 2335-2341.

28. Sudowe, S., Specht, C., Kolbe, L. and Kolsch, E. (1995) In situ dormancy of B lymphocytes programmed for an $\mathrm{IgE}$ antibody response and their sudden release from unresponsiveness under in vitro conditions. Int. Immunol. 7, 1799-1807.

29. Arps, V., Sudowe, S., and Kolsch, E. (1998) Antigen dosedependent differences in $\mathrm{IgE}$ antibody production are not due to polarization towards Th1 and Th2 cell subsets. Eur. J. Immunol. 28, 681-686.

30. Viola, J.P., Kiani, A., Bozza, P.T. and Rao, A. (1998) Regulation of allergic inflammation and eosinophil recruitment in mice lacking the transcription factor NFAT1: role of interleukin-4 (IL-4) and IL-5. Blood, 91, 22232230.

31. Coffer, P.J., Schweizer, R.C., Dubois, G.R., Maikoe, T., Lammers, J.W. and Koenderman, L. (1998) Analysis of signal transduction pathways in human eosinophils activated by chemoattractants and the T-helper 2-derived cytokines interleukin-4 and interleukin-5. Blood, 91, 25472557.

32. Doherty, M.J. and Easty, D.L. (1989) Inflammatory and immunological cell profiles in a rat model of conjunctival immediate hypersensitivity. Clin. Exp. Allergy, 19, 449-455.

33. Carreras, I., Carreras, B., McGrath, L., Rice, A. and Easty, D.L.E. (1993) Activated T cells in an animal model of allergic conjunctivitis. Br. J. Ophthalmol. 77, 509-514. 